\title{
AUTOMATION OF REPORT GENERATION FOR FUNCTIONAL TESTING - E-SERVICES OPERATOR
}

\section{Rogelio Cohello}

National University Federico Villarreal, (Peru).

E-mail: rcohello@unfv.edu.pe

ORCID: https://orcid.org/0000-0001-5526-5231

\section{Ivan Petrlik}

National University Federico Villarreal, (Peru).

E-mail: ipetrlik@unfv.edu.pe

ORCID: https://orcid.org/0000-0002-1201-2143

Karin Rojas

National University Federico Villarreal, (Peru).

E-mail: krojasr@unfv.edu.pe

ORCID: https://orcid.org/0000-0002-6867-0778

Jorge Mayhuasca

National University Federico Villarreal, (Peru).

E-mail: jmayhuasca@unfvedu.pe

ORCID: https://orcid.org/0000-0002-6465-4738

\section{Citación sugerida:}

Cohello, R., Petrlik, I., Rojas, K., y Mayhuasca, J. (2022). Automation of report generation for functional testing - E-Services Operator. 3C Tecnología. Glosas de innovación aplicadas a la pyme, Edición Especial, (febrero 2022), 257-267. https://doi.org/10.17993/3ctecno.2022.specialissue9.257-267 


\section{ABSTRACT}

Technology advances every day because the business world should not be left behind in it, so there is the adoption of new ways of doing business. This is how ICT (Information and Communication Technologies) plays a key role in these new companies converting traditional processes such as bringing your customers through a web converting to e-Commerce, to a digital process.

Due to the rise of ICT has been the implementation of electronic billing systems, this type of systems come to stay; improvements are given based on an already predetermined structure, mapping in a better way the taxes and operations of taxpayers. Then, this type of business implies having well-trained IT and accounting staff that allows the online sending of the CPE (electronic receipts).

Therefore, this project seeks to improve an internal process in the development phase of the OSE BIZ LINKS that grants validity to electronic receipts, for we will use tools that can be reusable over time, such as Data-Driven Testing, which is a testing technique that has as its pillar two types of data: real data (functional test results) and expected data (results that should have each functional test case), making a comparison of both proceedings to report according to each data compared in this process.

\section{KEYWORDS}

ICT, Electronic bill, Electronic receipts, Data-Driven Testing, TDD, Reporting. 


\section{INTRODUCTION}

In Peru the electronic invoicing process dates to 2012, where everything starts with a pilot project; by the end of 2013 SUNAT (National Superintendence of Customs and Tax Administration) by RS No. 374-2013 designated 239 companies that, from October 1 of that year, begin the implementation of electronic invoicing, where you should first be approved to issue electronic vouchers (invoice, ticket, electronic notes) ( $R N^{\circ}$ 374-2013 sunat).

In this context, BIZLINKS is born, a company approved to the PSE and OSE service; having as main functions to validate and declare the electronic receipts. These validation processes.

With this purpose, BIZLINKS SAC proposes to make use of the reengineering to carry out a restructuring of the OSE BIZLINKS, with the objective of having a better adaptation and response to the changes. For the realization of this project, the company took its own human resources and will make the necessary arrangements for the delivery of an optimal service. Functional testing, regression and stress testing will be used as quality activities. Within this framework, to reduce the evaluation time of the functional tests, the data-driven Testing technique will be added.

\subsection{CONCEPTUAL FRAMEWORK}

\subsubsection{JAVA LANGUAGE}

Java is an object-oriented programming language, the facility offered by this language is to be executed on any device through JVM, it can be applied even in mobile devices providing portability (Mitsunori, 2018, p.2).

It should be noted that since its inception was open sources and has remained so until today, being one of the programming languages that remain with greater labor demand. 


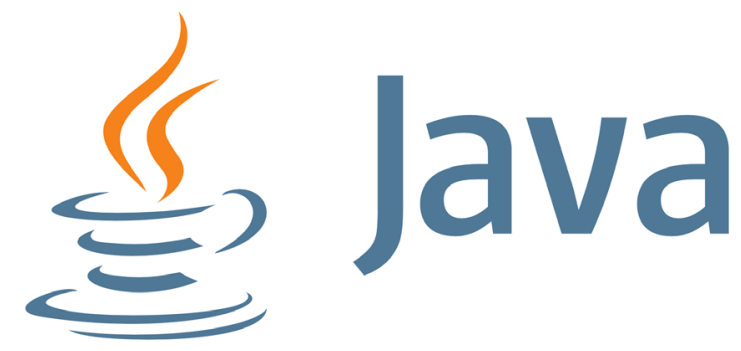

Figure 1. Java logo.

Source: own elaboration.

\subsubsection{BUSINESS PROCESS MANAGEMENT (BPM)}

Process management is considered a discipline, which combines technology and methodology; it aims to improve internal processes by providing better resource management in an organization.

The technique of process modeling, execution, and measurement is a strategy that can be performed using this BPM technology.

According to Laurentiis (2003), he defines it is "a set of activities or specific work in a specific place that is performed by people or systems, having a clear beginning and end; with several specific inputs and outputs".

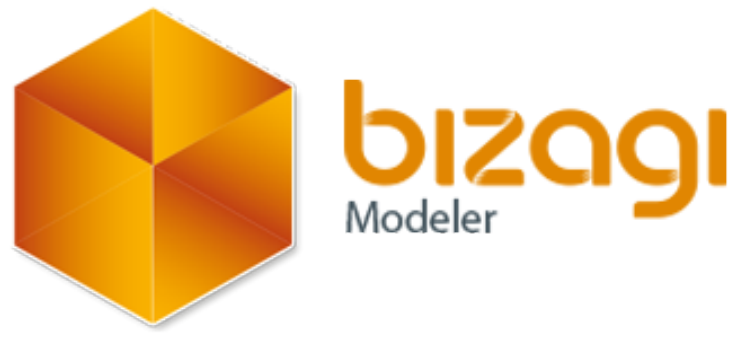

Figure 2. Bizagi logo.

Source: own elaboration.

\subsubsection{TESTNG FRAMEWORK}

According to Nordeen (2020), TestNG is an automation testing framework in which NG stands for "Next Generation". TestNG is inspired by JUnit which uses the annotations(@). 


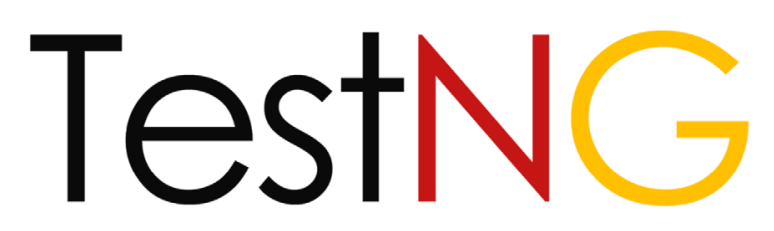

Figure 3. TestNG logo.

Source: own elaboration.

\subsubsection{MICROSOFT SQL SERVER MANAGEMENT}

Microsoft allows us the free and easy-to-understand use of its SQL Server database engine. In this we will be able to create the database structure considering the appropriate fields to compare (code, file name, description).

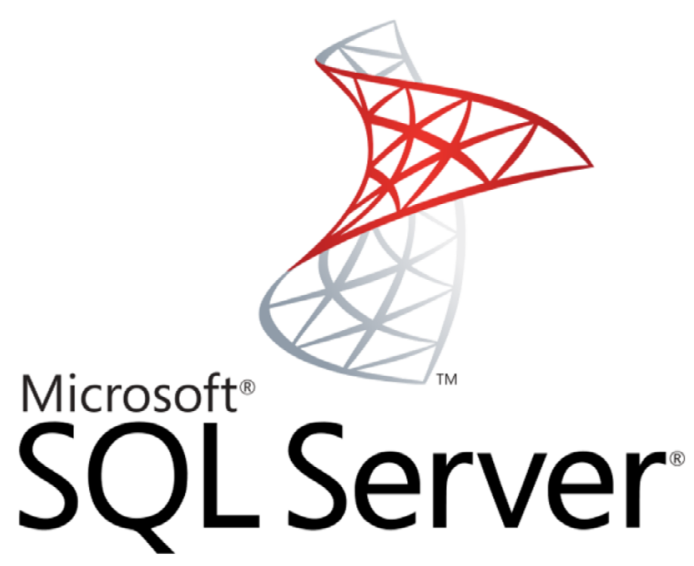

Figure 4. Microsoft SQL Server Management. Source: own elaboration.

\subsubsection{DATA-DRIVEN TESTING}

It is a technique of testing software abbreviation TDD provides a great opportunity to accurately determine using predefined scenarios by the data input and output. 


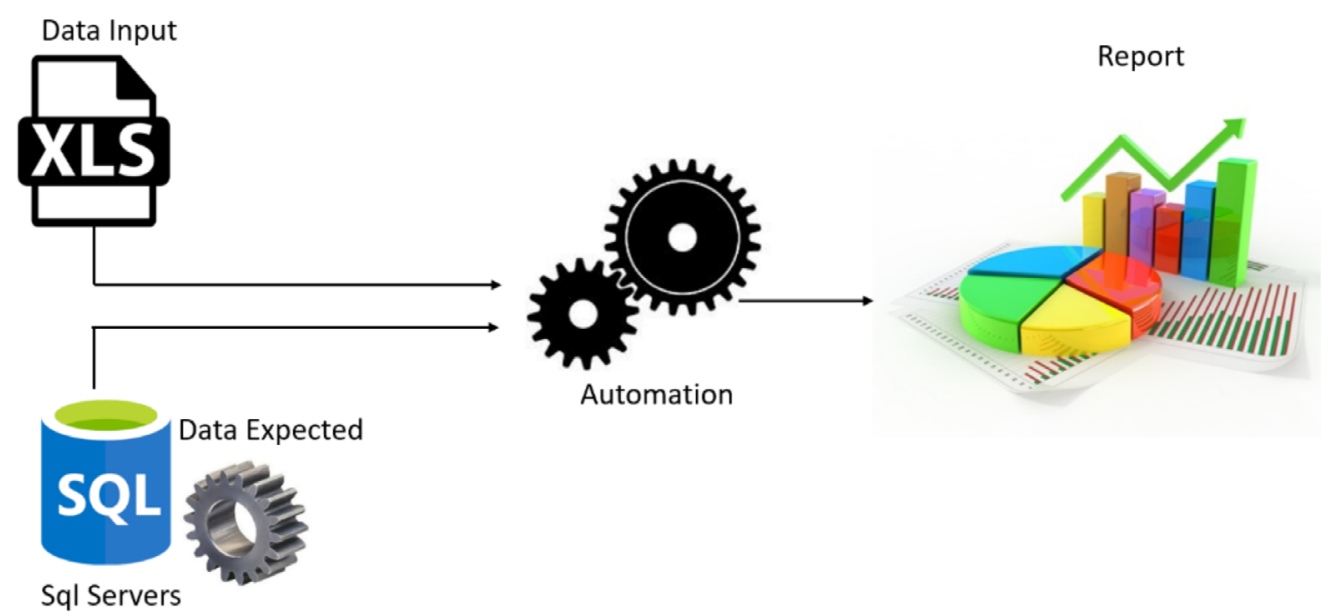

Figure 5. Data Driven Testing.

Source: own elaboration.

\section{METHODOLOGY}

\subsection{TYPE OF RESEARCH}

This research project allows us to apply knowledge, tools to improve the processes of the system therefore it is Applied Research.

\subsection{KANBAN METHODOLOGY}

Kanban is an agile framework, meaning the Japanese "Kan" visual and "Ban" cards; its origins are given with the Japanese company Toyota, which observed how in the U.S. supermarkets as these replenished only the missing did not have either an excess. From this scenario, Toyota coupled as pillars of its production system the just in time and automation under a human perspective (Laurentiis, 2003).

Kanban cards or sticky sheets, the quantity will be necessary according to what is to be produced; the description is minimal, direct, and concrete, often codes are placed for the recognition of the activity. However, no matter how visual these cards are, they do not replace the need for verbal communication. 
Kanban boards have divisions for 3 states, do, doing, and done basically. Making a mix of methodologies like Kanban and Scrum is possible because both are considered agile methodology.

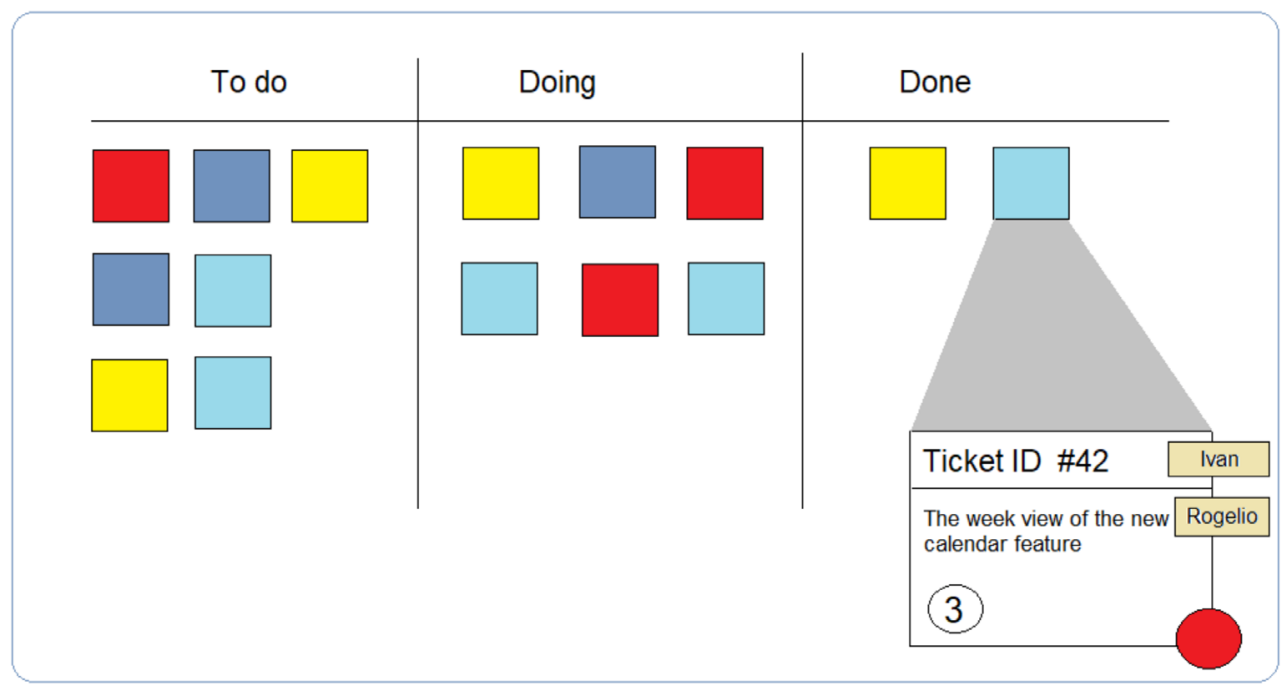

Figure 6. Kanban Board.

Source: own elaboration.

\subsection{METHODOLOGICAL PROPOSAL}

The activities to use in the development stage will be established in the process flow, in order to recognize the inputs, internal processes and outputs, these are intended to ensure that the result of functional testing has been correct.

For this purpose, the following strategy is established:

1. Organize requirements.

2. Design current and improvement process flow.

3. Collection of answers obtained in functional tests.

4. Database creation and data entry.

5. Solution programming.

6. Testing of the system to be implemented.

7. Use of live solution. 


\section{Organize requirements}

Requirements often describe what the program or system is expected to do, in our case, we will have two types of requirements found; functional requirements and non-functional requirements.

According to the study for this project as a functional requirement must be considered, which will show the failed and correct cases, the filters to be considered, how long it will take graphical display.

\section{Design the current process flow and improve}

In this section it is currently contemplated which are the steps to follow to obtain the report of the functional tests, comparing them of the processes that will be considered with the improvement (Crispin \& Gregory, 2009; Kaner, 2008).

In this way, it will be possible to verify if the improvement is covering all the necessary processes

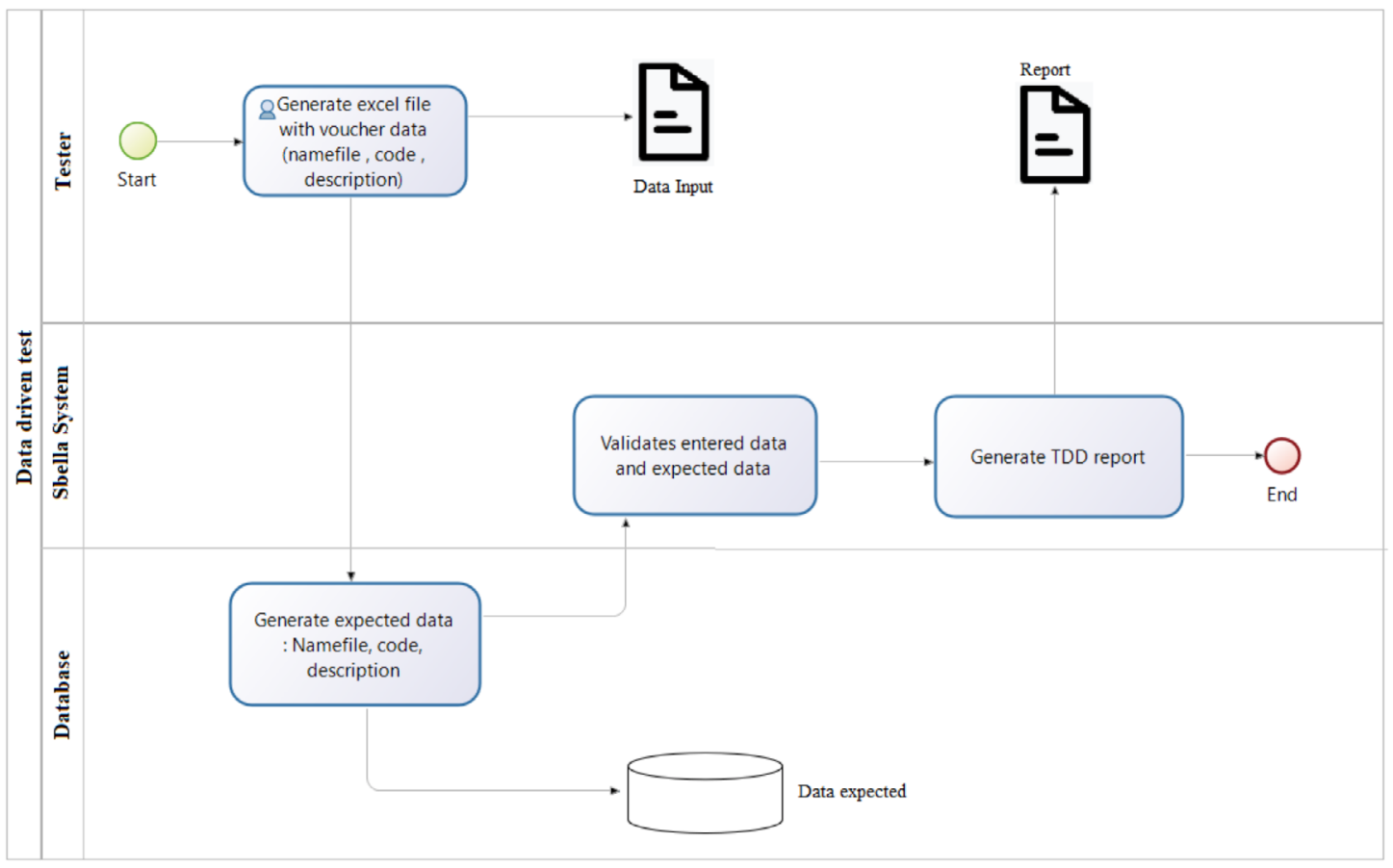

Figure 7. Current process flow.

Source: own elaboration. 


\section{Collection of answers obtained in functional tests.}

At this point, it is necessary to clarify that TDD is a support technique for the evaluation of functional tests but it is not part of them.

Therefore, first of all, the functional tests must be executed and the answers must be recorded in a file and then this file must be considered as the base for the TDD technique since this file will be checked with the database.

On the validity of the functional test case, it will be accepted or failed according to the data in the database.

\section{Database creation and data entry}

For this step, we consider setting up a simple database that allows us to store the desired data. Queries will be performed under the file name (name file field) because each file contains only one registered response code.

\section{Solution Programming}

According to ISO (2005), In this case, it is necessary to define the participants of the improvement process and declare them in classes together with their methods, to have clear after investigating the way of working of the framework to use, and how to manage in a better way than knowledge, the information crossing must be done.

The elements are also identified as the Excel description field, which will be read and considered, the division of the text will be taken to evaluate a section as the other does not belong to the expected response.

\section{System testing implement}

According to Beck (2002), Once the solution has been programmed, the system execution should be carried out and the errors should be reviewed in order to present them and make documentation in which the possible solutions are described. Finally, the revised aspects must be solved for the next execution of the system. 


\section{Use of live solution.}

As the last step, the system will have fulfilled its objective, which is to validate the results of more

\section{RESULTS}

The results obtained were favorable for the proposed objective, which was to reduce the testing time and to have an intuitive result that allows us to give feedback in time, communicating errors early and thus favoring the development of the OSE BIZLINKS.

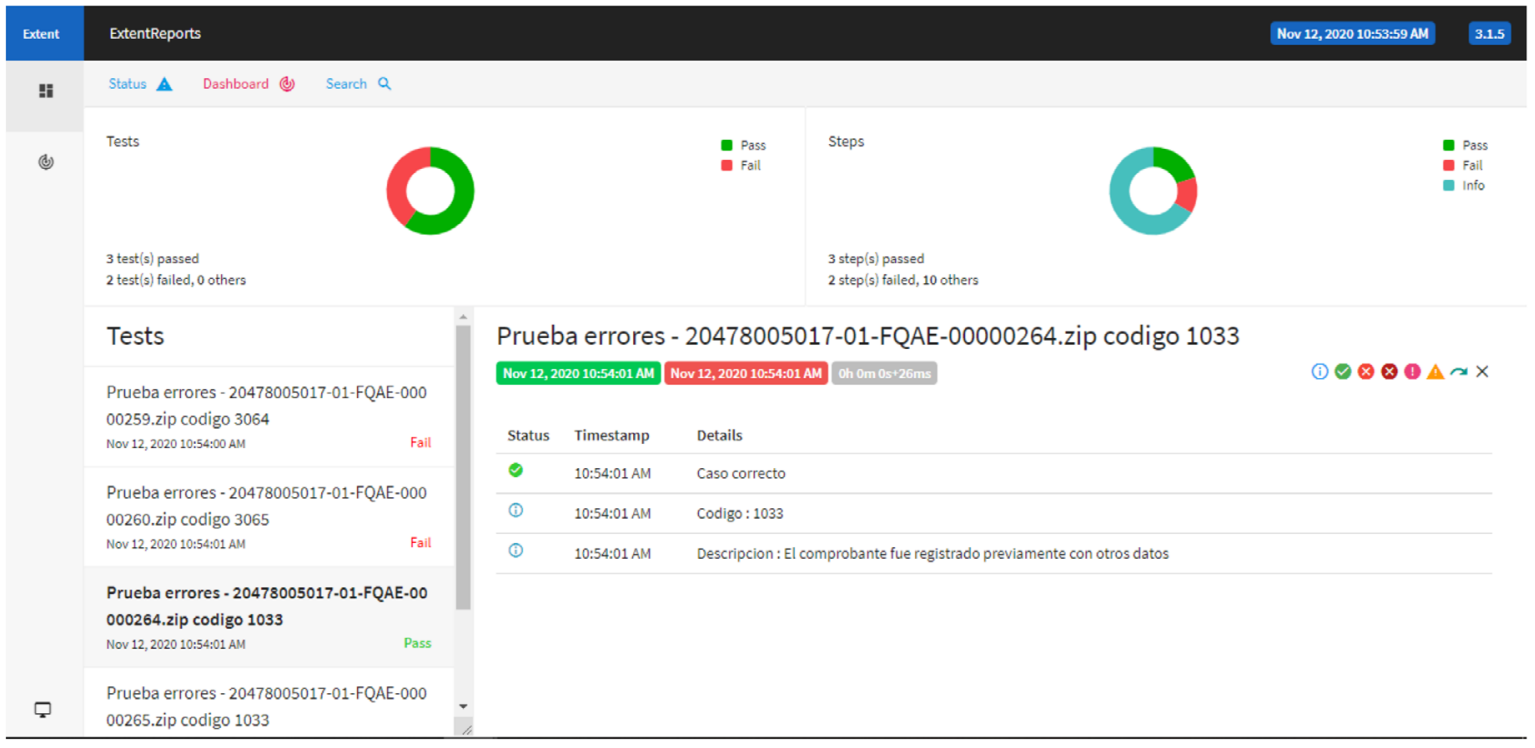

Figure 9. Report generated.

Source: own elaboration.

\section{CONCLUSIONS}

This project shows a data-driven testing technique, in this case the flow is defined by abstract test cases that when executed become part of specific test case. This type of application allows us to communicate easily, early, and often, which allows us to be part of the Agile project, this way we would be giving frequent feedback (Fester, 2018). 


\section{EVALUATION}

The trust given by the supervising staff who were always kind enough to resolve any doubts that one may have in the process of generating a program is valued. The experience of teamwork and effective communication of each team member. The knowledge gained in this project will be permanent and becomes an asset of the company which generates satisfaction to one as a collaborator. Also, this project helped to have a broader view of the world of software quality (Fewter \& Graham, 1999; Crispin \& Gregory, 2008; Kaner et al., 2006; Cardoso et al., 2018).

\section{REFERENCES}

Beck, K. (2003). Test-driven development: by example. Addison-Wesley Professional.

Cardoso, E. P., Alarcón, F., \& Pava, E. A. H. (2018). Diseño de un sistema informático (software) para automatizar los procesos contables en el sector mecánico automotriz del régimen simplificado. Revista Innova ITFIP, 2(1), 62-70.

Crispin, L., \& Gregory, J. (2009). Agile testing: A practical guide for testers and agile teams. Pearson Education.

Fester, M., \& Graham, D. (1999). Software test automation (pp. 211-219). Addison-Wesley.

Kaner, C., Bach, J., \& Pettichord, B. (2008). Lessons learned in software testing. John Wiley \& Sons.

Laurentiis, R. (2003). BPMS, tecnología para la integración y orquestación de procesos, sistemas y organización. http://www.rrhhmagazine.com/articulos.asp

Mitsunori, O. (2018). Fundamentals of Java Programming. Springer.

Resolución de superintendencia $N^{\circ} 374-2013 /$ sunat de 27 de diciembre 2013.

RTGA (Firm). SG 167. (1992). Software considerations in airborne systems and equipment certification. RTCA, Incorporated. 